\title{
Design of Multi-Part Mould for Production of a Medium-Large Carbon Fibre Component
}

Michal Skovajsa, Frantisek Sedlacek, Martin Mrazek

Faculty of Mechanical Engineering, University of West Bohemia in Pilsen. Univerzitní 8, 30001 Plzen. Czech Republic. E-mail: skovi@kks.zcu.cz, fsedlace@kks.zcu.cz,mrma@kks.zcu.cz

This paper deals with the design of a multi-part mould for the production of a carbon fibre medium-large component. The design and forming of a medium-large component which is defined by a closed structure and has high demands on dimensional accuracy is a very complex process. The goal was to design a simple manufacturing process for a negative mould. There are many different ways to design and manufacture this type of mould. One possible solution was designed and tested. This paper describes the case study of a carbon fibre monocoque of a small racing car. The first step was to define the requirements of the final product and the negative mould. The next step was to design a multi-part mould with one main parting plane and two minor parting planes and define the number of steps needed to build a negative mould. Another problem is how to define the position of the general anchor points that determine the final product. In this case the procedure of transferring the hole from a positive to a negative mould was defined.

Keywords: Negative Mould, Positive Mould, Carbon fibre, Forming, Monocoque

\section{Introduction}

Components produced from composite material like Carbon Fibre Reinforced Polymer (CFRP) have become an integral part of all sectors. This research paper deals with the design of a multi-part negative mould for producing carbon fibre prototype parts. The design and forming of a medium-large component which is defined by a closed structure and has high demands on dimensional accuracy is a very complex process. Multi-part moulds with parting planes are typically used for the production of these components.

\section{Case study}

This paper describes a case study of a carbon fibre monocoque for a small racing car, see Fig. 1. For this type of component, emphasis is placed on dimensional accuracy, integral structure and external surface finish. Randle, Horner and Newey [1] describe a partial process for manufacturing a glued monocoque of a Formula 1 RB6. This publication defines the accuracy of the monocoque structure to $\pm 0.05 \mathrm{~mm}$. The shell space frame or 'monocoque' is a composite of two words 'mono' (which means 'one' in Greek) and 'coque' (which means 'shell' in French). It is a structure that transmits the load of the outer shell (car body), or it is a structural component of the car with body integration. [2] A CFRP monocoque chassis is manufactured at high temperature and pressure in an autoclave. The temperature for manufacturing can be from $100 \div 250{ }^{\circ} \mathrm{C}[3]$ based on the resin glass transition temperature requirement. The pressure for manufacturing can be from $1 \div 10$ bar based on the type of CFRP and the required properties of the monocoque chassis. The production conditions therefore influence the mould material used. [4, 5]
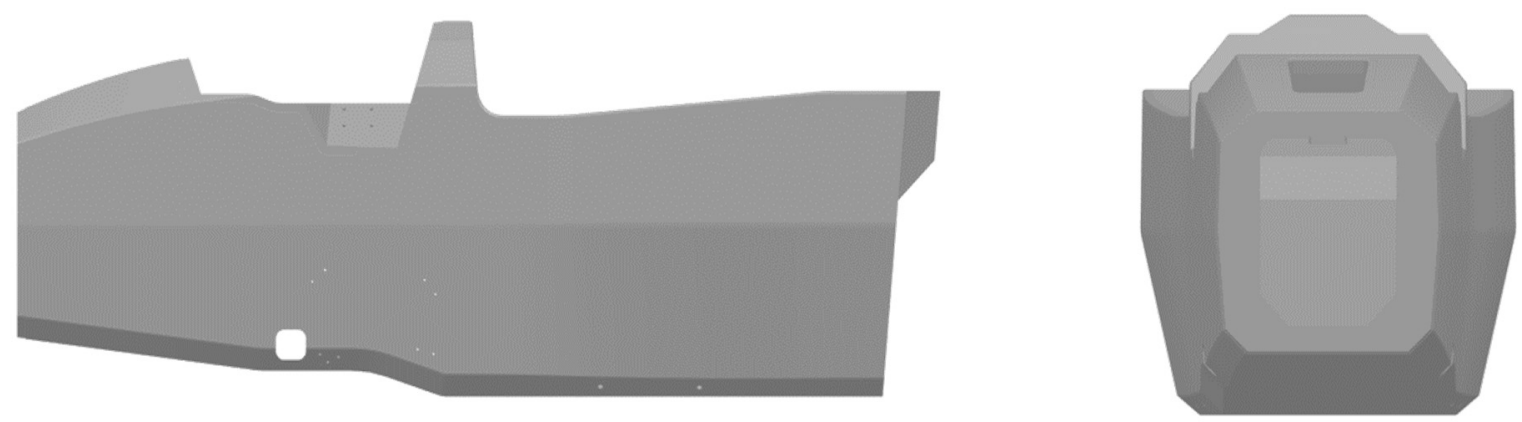

Fig. 1 Side view of monocoque (left); Front view of monocoque (right) 
Due to the production process, the character of the monocoque load, which is torsionally stressed, and the dimensional requirements, it is not advisable to divide the monocoque into several parts and then to glue it. Therefore, it is necessary to design a manufacturing process that ensures the integrity of the entire structure and all these requirements. A procedure was designed to ensure the monocoque is manufactured in one piece. The monocoque chosen for the case study is $1677 \mathrm{~mm}$ long, $617 \mathrm{~mm}$ high, and $635 \mathrm{~mm}$ wide. The total outer surface of the monocoque is $3.15 \mathrm{~m} 2$. This monocoque was made from carbon fibre prepreg in an autoclave in two stages. In the first stage the outer shell was produced at a temperature of $120^{\circ} \mathrm{C}$ and with total overpressure of $4 \mathrm{bar}$. In the second stage the outer shell was laminated on the inner layer simultaneously with an aluminium honeycomb core. The inner layer was cured at a temperature of $120{ }^{\circ} \mathrm{C}$ and a total overpressure of $2 \mathrm{bar}$. This process was determined according to the publication. $[6,7,8]$

\section{Forming}

If we consider manufacturing the enclosure structure with the requirement for dimensional accuracy of the outer surface, we can replace this structure with a pipe. The manufacturing process of this part can be done in various ways according to the type of moulds used:

One-step negative mould, this solution is shown in Fig. 2. The disadvantage of this solution is the high weight of the mould, meaning complicated handling during manufacturing of the final product and disassembling the mould; larger mould dimensions; less shape stability; more demanding machining. The advantage is greater accuracy of the product, which is determined by reducing the number of process steps. This type of mould is used in smaller moulds which are used for serial production. The moulds may be made for example from an aluminium alloy, medium density fibreboard or high density polyurethane board. $[9,3]$

Two-step negative mould, this solution is shown in Fig. 3. Production of a negative mould using a positive product model. The disadvantage of this solution is the reduced accuracy due to an increase of technological steps. The advantage is the low weight of the negative mould; the material of the mould can be the same material as for the final product, thereby ensuring the same thermal expansion in the manufacturing process. $[9,3]$

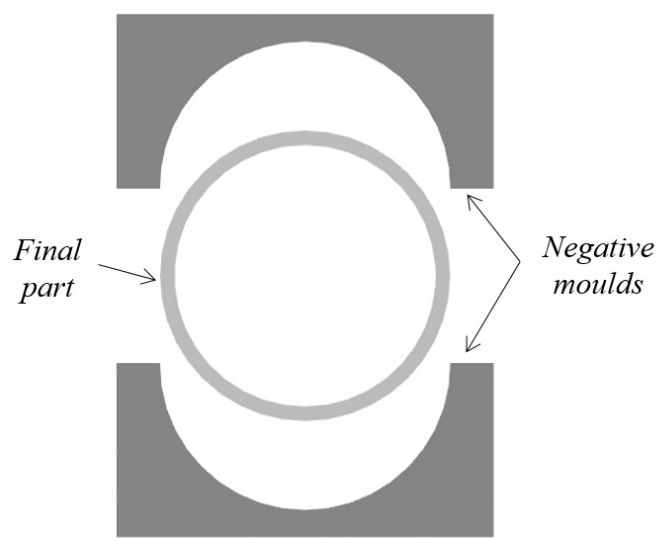

Fig. 3 One-step negative mould solution

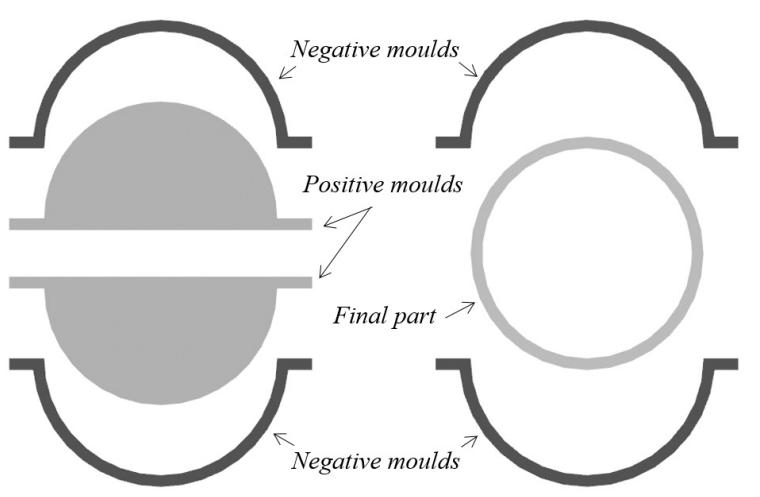

Fig. 3 Two-step negative mould solution

From the perspective of the selection of direction and the position of the main parting plane, three basic options were defined: horizontal, vertical and both directions, see Fig. 4. The selection of parting planes depends on the specific technical solution of the final product. Secondary parting planes are required for more complex shapes. These planes ensure the mouldabilty of the final product.
Horizontal parting plane

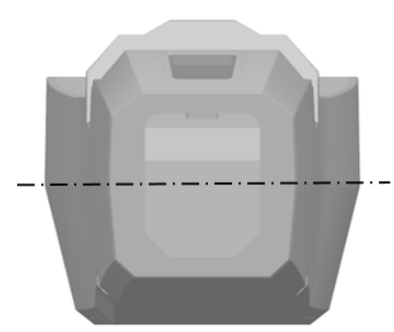

Vertical parting plane

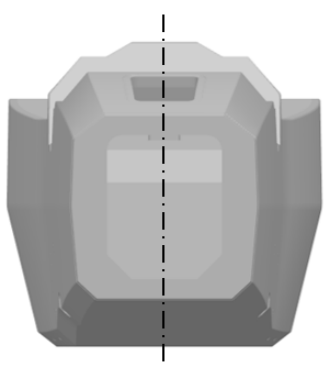

Both parting plane

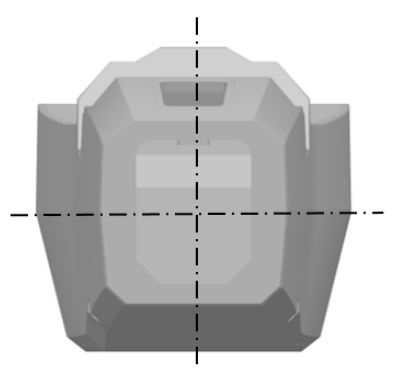

Fig. 4 Types of main parting planes 


\section{Negative Mould Design}

For the design of the mould, it is important that the part itself is designed so that it is mouldable. This is primarily the draft angle. This draft angle ensures that the part can be removed from the mould. The draft must be greater than or equal to $1.5^{\circ}$. The mould is designed with a horizontal parting plane which is in the middle of the monocoque. A draft greater than $1.5^{\circ}$ is maintained in all cross-sections of monocoque below and above the horizontal parting plane. This is shown in Fig. 5.

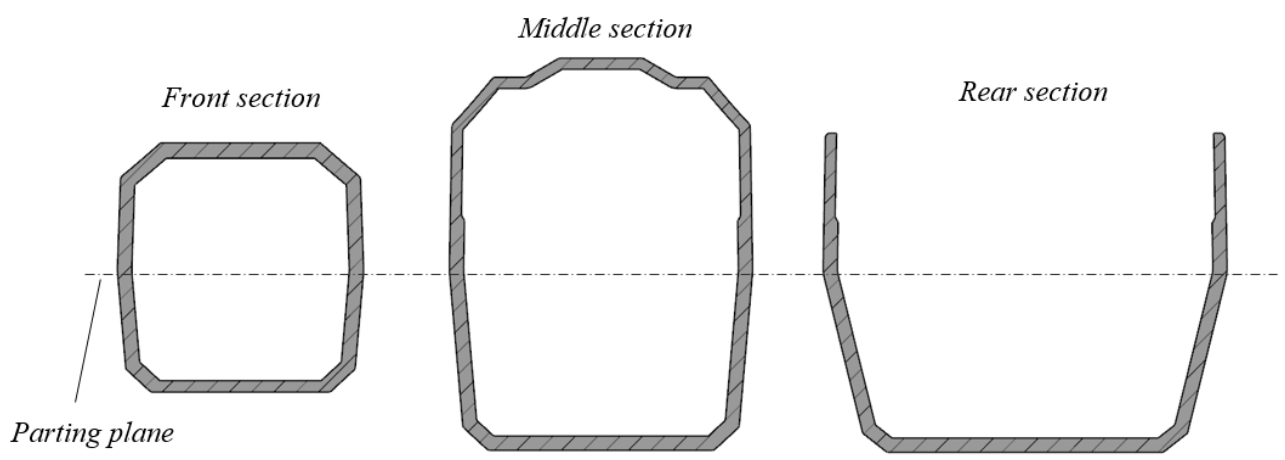

Fig. 5 Front, middle and rear cross section

Due to the undercut located in the rear part of the monocoque, it is not possible to maintain the positive draft for the upper part of the mould in the longitudinal section. Therefore a minor parting plane was designed at the rear of the upper mould, see Fig. 6. The rear part of the mould was created and this part was disassembled in a backwards direction. Due to the service hole which must be made with an inner flange, located in the front part of the monocoque, it was not possible to disassemble the upper and lower moulds. Therefore a minor parting plane was designed in the upper and lower moulds in the front region, see Fig. 6.

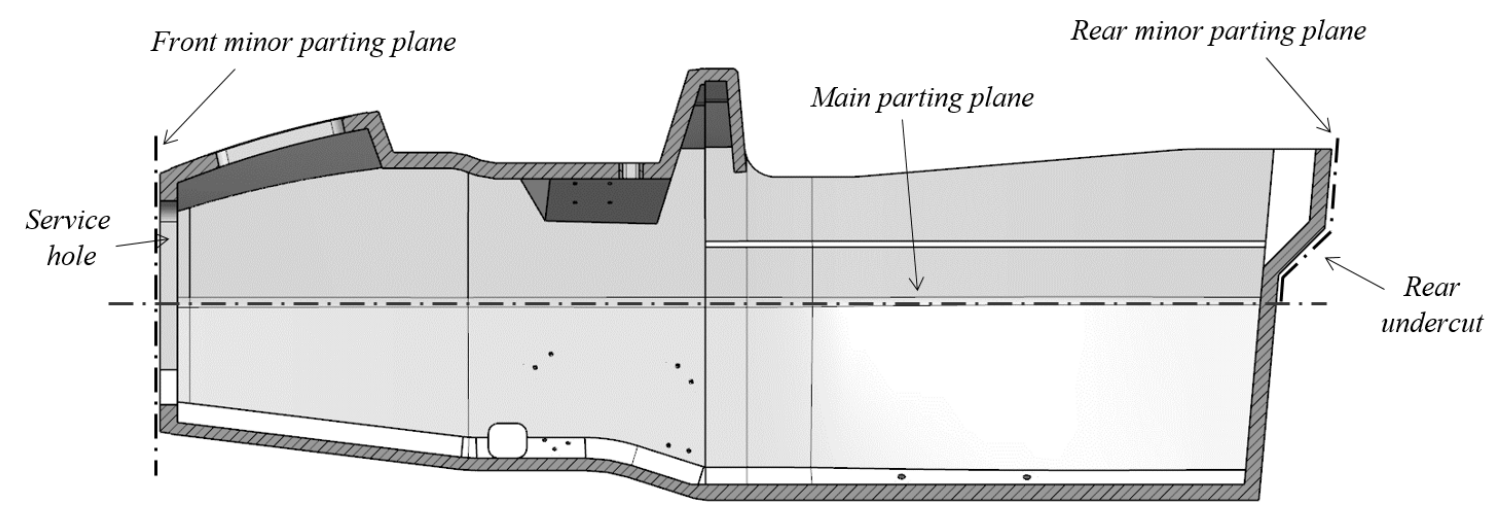

Fig. 7 Main and minor parting planes

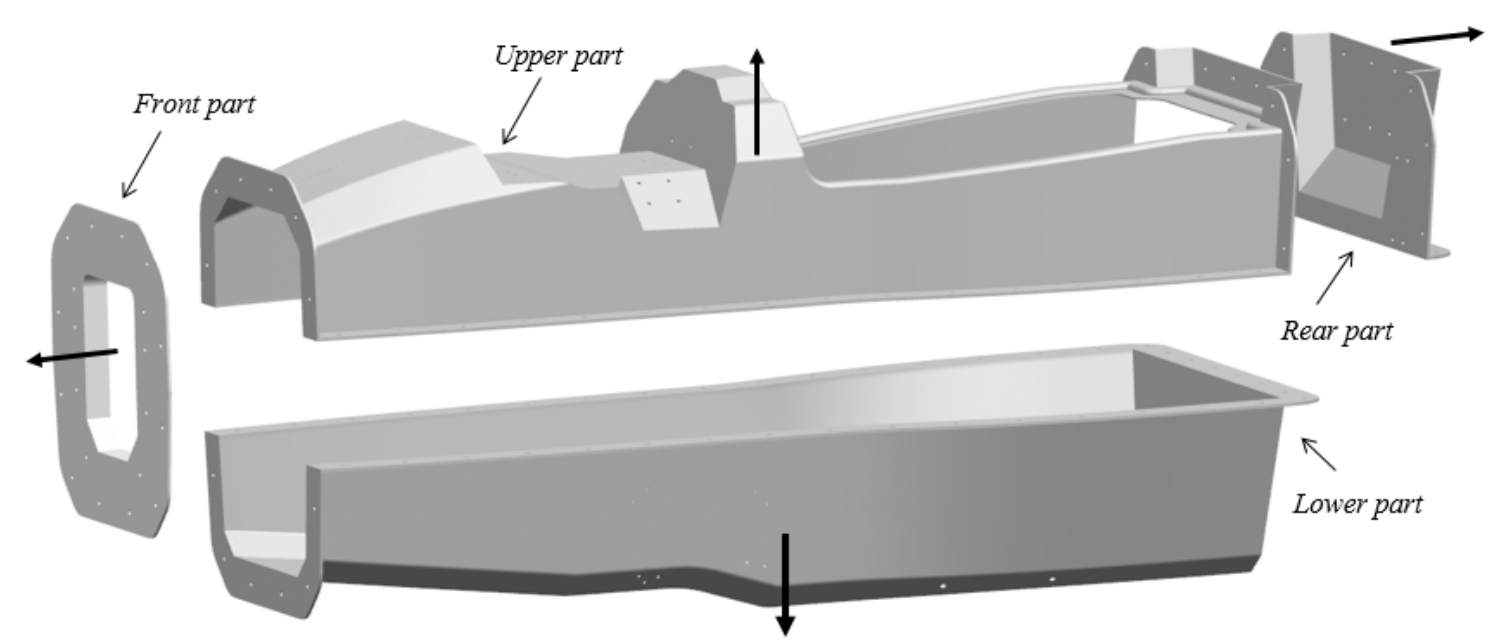

Fig. 7 Disassembly of negative chassis mould 
The goal was to achieve the lowest number of moulds in order to increase the accuracy of the final product. In this case, the moulds were designed with one main and two minor parting planes. The final mould consists of four parts, see Fig. 7. The moulds were connected by a screw connection using M8 size bolts. To ensure this connection, a flange was created on each mould. The flanges were $60 \mathrm{~mm}$ wide. 32 screw connections were used in the main horizontal parting plane, which had a pitch of $100 \mathrm{~mm}$. In both minor parting planes 30 bolts were used with approximately $80 \mathrm{~mm}$ pitch.

CFRP and high temperature epoxy resins were used for the negative mould. The negative mould was made by wet hand contact lamination. The following layer structure was defined for producing the negative mould. The first step was to apply the epoxy tooling gelcoat in two layers, which ensures good surface roughness and a hard outer surface. Next was applied: one layer of ultra-lightweight fibreglass chopped strand matting ideal for use as a fine surface layer with area weight 100 g.m-2; one layer of carbon fibre roving with length weight 200 g.m-1, which was applied only at the corners; one layer of carbon fibre reinforcement twill with area weight 200 g.m-2; six layers of carbon fibre reinforcement twill area weight 400 g.m-2. The sequence of all the layers is listed in Tab. 1. The total time for application of all the layers was approximately 10 hours. A resin epoxy with a long cure time (approximately 24 hours) and a glass transition temperature above $130{ }^{\circ} \mathrm{C}$ was used for lamination. This glass transition temperature was selected based on the material which will be used to produce the final monocoque. The monocoque will be cured at $125^{\circ} \mathrm{C}$. Using carbon fibre reinforcement for producing the negative mould ensures the dimensional stability at high temperature during the curing of the final monocoque.

Tab. 1 The sequences of all layers.

\begin{tabular}{|c|c|c|}
\hline no. of layer & Material & Duration of application for lower part of mould \\
\hline 1 & Epoxy Gelcoat & application 25 minutes; 30 minutes wait for next layer \\
\hline 2 & Epoxy Gelcoat & application 25 minutes; 30 minutes wait for next layer \\
\hline 3 & CFRP - Roving $200 \mathrm{~g} \cdot \mathrm{m}^{-1}($ corner $)$ & application 40 minutes \\
\hline 4 & Fibreglass matting $-100 \mathrm{~g} \cdot \mathrm{m}^{-2}$ & application 30 minutes \\
\hline 5 & CFRP - Twill $200 \mathrm{~g} \cdot \mathrm{m}^{-2}$ & application 50 minutes \\
\hline 6 & CFRP - Twill $400 \mathrm{~g} \cdot \mathrm{m}^{-2}$ & application 60 minutes \\
\hline 7 & CFRP - Twill $400 \mathrm{~g} \cdot \mathrm{m}^{-2}$ & application 60 minutes \\
\hline 8 & CFRP - Twill $400 \mathrm{~g} \cdot \mathrm{m}^{-2}$ & application 60 minutes \\
\hline 9 & CFRP - Twill $400 \mathrm{~g} \cdot \mathrm{m}^{-2}$ & application 60 minutes \\
\hline 10 & CFRP - Twill $400 \mathrm{~g} \cdot \mathrm{m}^{-2}$ & application 60 minutes \\
\hline 11 & CFRP - Twill $400 \mathrm{~g} \cdot \mathrm{m}^{-2}$ &
\end{tabular}

\section{Positive Mould Design}

The lower and upper positive moulds consist of a main block and additional screwing parting planes which are made of waterproof plywood, see Fig. 8. By

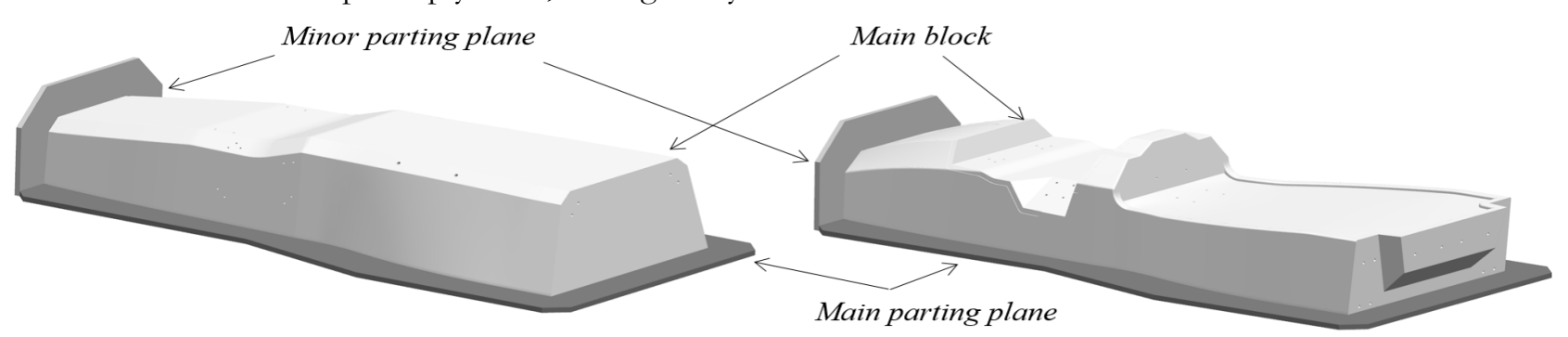

Fig. $\boldsymbol{8}$ Lower positive mould (left); Upper positive mould (right)

The material of the main block was selected based on price, final surface and manufacturing. The two main materials for producing the mould were compared. The main property values are given in Tab. 2 . The first one was medium density fibreboard E1 (MDFE1) and the second one was Sika Block M700 (SBM700). MDF is a wood-based panel material made by bonding together wood fibres with a synthetic resin using this additional screwing plane, the production time was shortened and the production process was simplified. The main block was manufactured on a CNC milling machine. 
Tab. 2 Material properties

\begin{tabular}{|c|c|c|c|c|c|c|c|}
\hline & \multirow{2}{*}{$\begin{array}{c}\text { Density } \\
{\left[\mathrm{kgm}^{-3}\right]}\end{array}$} & \multirow{2}{*}{$\begin{array}{c}\text { Price } \\
{\left[\mathrm{EUR} \mathrm{kg}^{-1}\right]}\end{array}$} & $\begin{array}{c}\text { Bending } \\
\text { strength } \\
{[\mathrm{MPa}]}\end{array}$ & $\begin{array}{c}\text { Dimension } \\
{[\mathrm{mm}]}\end{array}$ & $\begin{array}{c}\text { Volume } \\
{\left[\mathrm{m}^{3}\right]}\end{array}$ & $\begin{array}{c}\text { Weight } \\
{[\mathrm{kg}]}\end{array}$ & $\begin{array}{c}\text { Price } \\
{[\mathrm{EUR}]}\end{array}$ \\
\hline $\begin{array}{c}\text { Medium Density } \\
\text { Fibreboard E1 }\end{array}$ & 670 & 1 & 17 & \multirow{2}{*}{ 1660x700x304 } & 0.353 & 236.5 & 236.5 \\
\cline { 1 - 4 } & & & 26 & & 247.1 & 1482.6 \\
\hline
\end{tabular}

Tab. 3 Comparison of materials

\begin{tabular}{|c|l|}
\hline Price & The price of SB-M700 is six times greater than using MDF-E1 \\
\hline Manufacturing & $\begin{array}{l}\text { Both materials can be manufactured by milling cutter. The difference is in chip formation, } \\
\text { see Fig. 9. SB-M700 produces normal integral shavings and MDF-E1 produces very small } \\
\text { shavings and a large amount of dust. }\end{array}$ \\
\hline Final Surface & $\begin{array}{l}\text { The surface after machining SB-M700 is very smooth and requires little manual finishing. } \\
\text { The surface after machining MDF-E1 is slightly shaggy and requires more manual finishing. }\end{array}$ \\
\hline Material & $\begin{array}{l}\text { SB-M700 is not absorbent. For surface glass finish it is enough to apply mould sealer. MDF- } \\
\text { E1 is partly absorbent. For surface glass finish it is necessary to apply 2-3 polyurethane fillers. } \\
\text { Between each layer it is necessary to manually sand the mould. }\end{array}$ \\
\hline
\end{tabular}
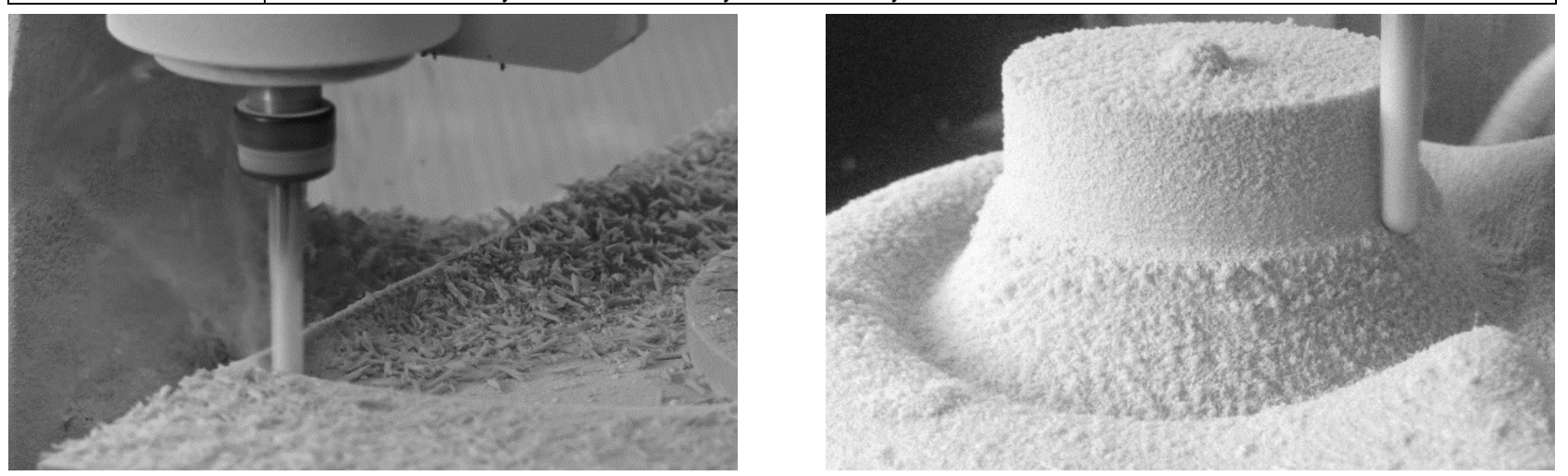

Fig. 9 SB-M700 Machining (left); MDF-E1 Machining (right)

Upper positive mould

Temporary parting plane

Upper negative mould
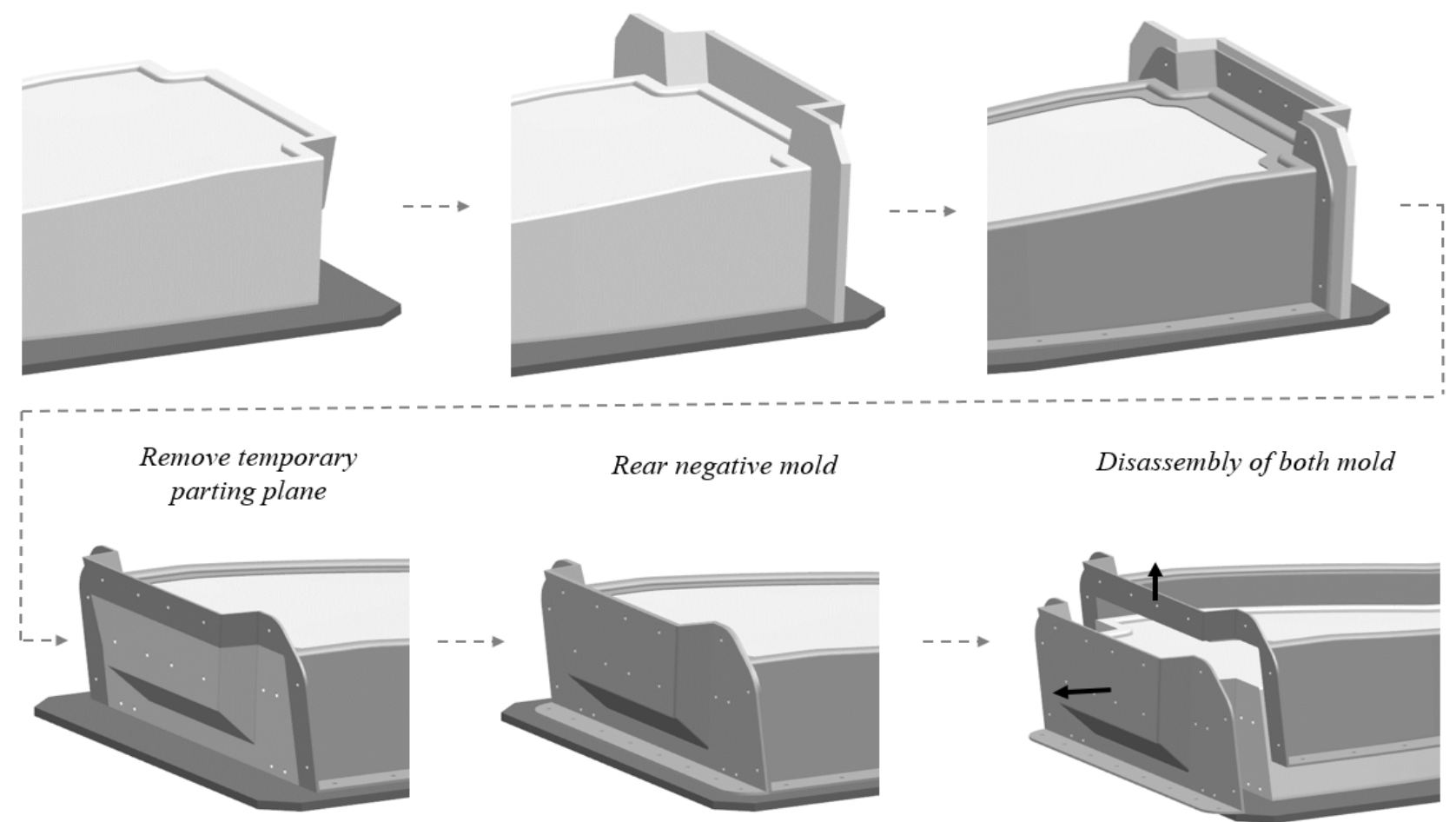

Rear negative mold

Disassembly of both mold
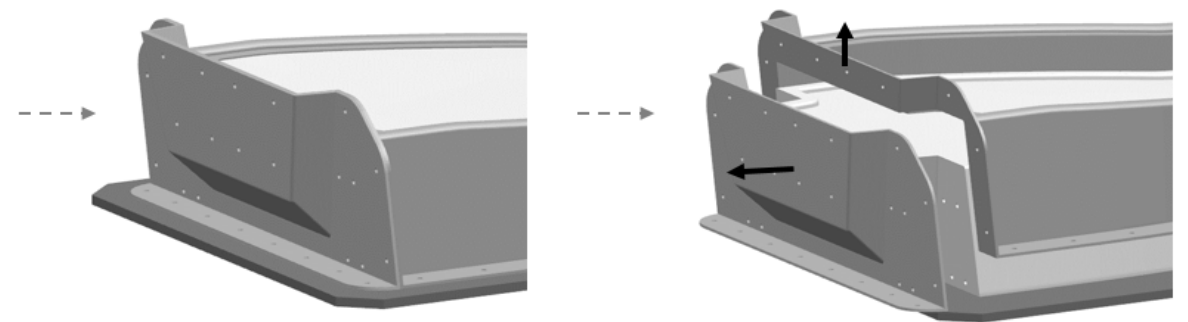

Fig. 10 Rear negative mould production process 
A temporary parting plane was used to produce the upper rear mould. The temporary parting plane was screwed to the rear part of the upper mould and it was made of waterproof plywood. In the first step, the main upper part was produced. The temporary parting plane was removed after curing the main upper mould. The upper main mould was left on the negative mould and it was replaced with the temporary parting plane. The rear part of the upper mould was created using this parting plane on the upper main mould. This transfer of the parting plane ensured the identical minor parting of both moulds. The whole procedure is shown in Fig. 10.

\section{Positive muold with hole}
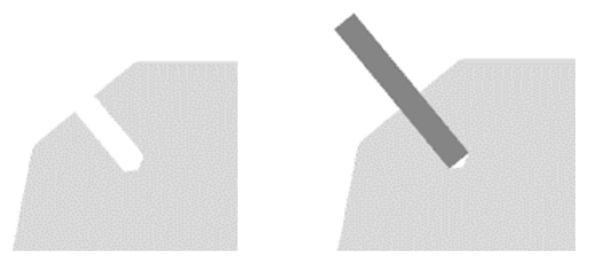
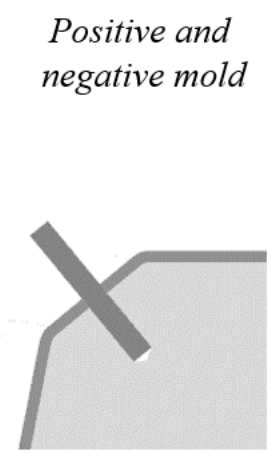

\section{Bracket holes}

The position of the anchorage points for the suspension, the rear of the frame, and other necessary components was ensured by using the hole-transfer method from the positive to the negative mould. The holes of each anchorage point were milled in positive moulds in a perpendicular direction to a specific surface. Teflon pins were inserted into these holes. Using Teflon ensures the easy disassembly of the pin from the assembly after curing the negative mould. The whole procedure is shown in Fig. 11.

Fig. 11 The process of transferring holes from positive to negative mould.

\section{Manufacturing}

CFPR mould was made to verify the manufacturing methodology described above. The total time for application of all the layers of the lower negative mould was approximately 10 hours. The total time for production full four parts negative mould was 3 days with 10 hours per day with 2 people. The complete multi-part mould weighs $38 \mathrm{~kg}$. The whole final product is shown in Fig. 12.

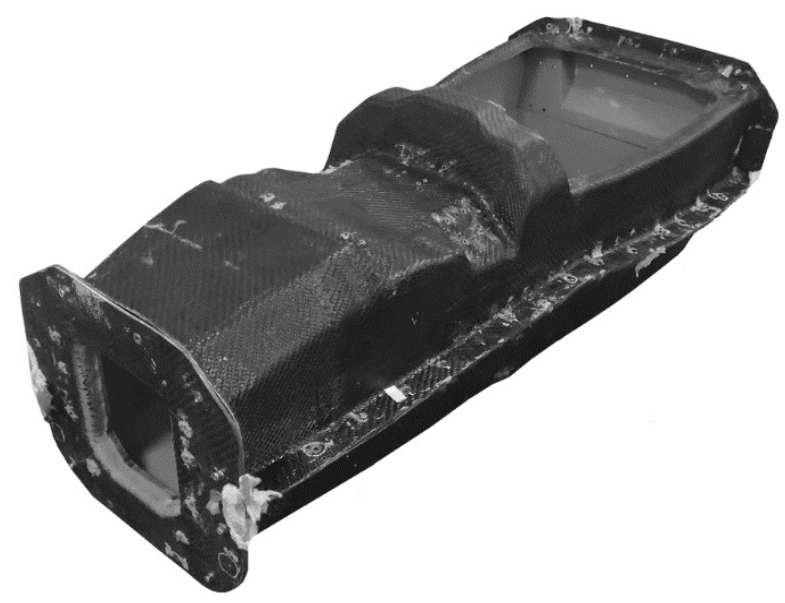

Fig. 12 Final manufactured negative mould

\section{Conclusion}

This paper deals with the design and manufacturing of a multi-part mould for producing a medium- large carbon fibre component. The question we wanted to answer was: What is the correct procedure for mould design and manufacturing? The goal of this paper was to design and describe the manufacturing process of a negative mould. Two variants of manufacturing process were defined. A two-step negative mould process was applied to the case study part. This paper used as a case study the carbon fibre monocoque of a small racing car. The monocoque which was chosen for the case study is $1677 \mathrm{~mm}$ long, 617 $\mathrm{mm}$ high, and $635 \mathrm{~mm}$ wide.

Two materials for manufacturing of positive mould with similar density of about $700 \mathrm{~kg} \cdot \mathrm{m}^{-3}$ were compared. SB-M700 is better material from the machining and final surface quality point of view. But the MDF was chosen for case study from the price point of view because it was six times cheaper than the polyurethane board and met all other requirements.

Production procedure of a negative mould, which has been described and tested in the manufacture of functional sample. This established manufacturing technology can be used to produce a similar mould.

The complete multi-part negative mould weighs 38 $\mathrm{kg}$. If we decided to produce a one-step negative mould by machining from MDF, then the weight of the negative mould would be approximately $500 \mathrm{~kg}$. In this case it would be very difficult to handle the mould and manufacturing final product. Therefore, a twostep mould is a better soliton for negative mould production. 


\section{References}

[1] S. RENDLE, C. HORNER, A. NEWEY. (2011). Red Bull Racing F1 Car Manual, p. 15. Haynes Publishing. UK. ISBN 0857338013

[2] J. NJUGUNA, ED. (2016). Lightweight Composite Structures in Transport: Design, Manufacturing, Anaysis and Performance, pp. 75 - 80. Woodhead Publishing. UK. ISBN 1782423257

[3] F. C. CAMPBELL JR. (2003). Manufacturing Processes for Advanced Composites, pp. 113-125. Elsevier Science. Netherlands. ISBN 9781856174152

[4] F. C. CAMPBELL. (2010). Structural Composite Materials. pp. 238 - 242. ASM International, USA. ISBN 1615030379

[5] F. C. CAMPBELL JR. (2011). Manufacturing Technology for Aerospace Structural Materials, pp. 310-340. Elsevier Science. Netherlands. ISBN 1856174956
[6] T. N. BITZER. (2012). Honeycomb Technology: Materials, Design, Manufacturing, Applications and Testing, pp. 80-82. Springer Science \& Business Media. Germany. ISBN 9780412540509

[7] HEXCEL COMPOSITES (2019). HexWebTM Prepreg Technology. pp. 16-19. Hexcel. [online: bttps://www.bexcel.com/Resources/Technology-Manuals]

[8] HEXCEL COMPOSITES (2019). HexWebTM Honeycomb Sandwich Design Tehcnology. pp. 21-22. Hexcel. [online: https://www.hexcel.com/Resources/Technology-Manuals]

[9] H. A. AISYAH, M. T. PARIDAH, M. H. SAHRI, U. M. K. ANWAR, A. A. ASTIMAR. (2016). Properties of medium density fibreboard (MDF) from kenaf (Hibiscus cannabinus L.) core as function of refining conditions. pp. 1-5. Elsevier Science. Netherlands. ISSN 13598368 